\title{
Erratum to the effect of RAS blockers on the clinical characteristics of COVID-19 patients with hypertension
}

\author{
Zheyong Huang ${ }^{1 \#}$, Jiatian Cao ${ }^{1 \#}$, Yumeng Yao ${ }^{2}$, Xuejuan Jin ${ }^{1}$, Zhe Luo ${ }^{3}$, Yuan Xue ${ }^{3}$, Chouwen Zhu ${ }^{4}$, \\ Yanan Song ${ }^{1}$, Ying Wang ${ }^{1}$, Yunzeng Zou ${ }^{1}$, Juying Qian ${ }^{1}$, Kaihuan Yu ${ }^{5}$, Hui Gong ${ }^{1}, J^{\prime} u n b o G^{1}$ \\ ${ }^{1}$ Shanghai Institute of Cardiovascular Diseases, ${ }^{2}$ Department of Infection Disease, ${ }^{3}$ Department of Critical Medicine, ${ }^{4}$ Department of \\ Gastroenterology, Zhongshan Hospital, Fudan University, Shanghai, China; ${ }^{5}$ Department of Hepatobiliary Surgery, Renmin Hospital of Wuhan \\ University, Wuhan, China \\ "These authors contributed equally to this work. \\ Correspondence to: Hui Gong, PhD and Junbo Ge, MD, PhD. Shanghai Institute of Cardiovascular Diseases, Zhongshan Hospital, Fudan University, \\ 180 Feng Lin Road, Shanghai 200032, China. Email: gonghui2005@fudan.edu.cn; junboge@126.com.
}

doi: $10.21037 /$ atm-2020-27

View this article at: http://dx.doi.org/10.21037/atm-2020-27

Erratum to: Ann Transl Med 2020;8:430

The effect of RAS blockers on the clinical characteristics of COVID-19 patients with bypertension

In the article entitled "The effect of RAS blockers on the clinical characteristics of COVID-19 patients with hypertension (1), there are some errors. In Table 2, the data about in hospital mortality should be deleted, because the correct data about in hospital mortality have been showed in Table 6. The Table 2 should be replaced by the following table. 
Table 2 Comparison of demographic and clinical characteristics of patients with COVID-19 between Group A (including RAS blockers treatment) and Group B (non-RAS blockers treatment)

\begin{tabular}{|c|c|c|c|}
\hline & Group A $(n=20)$ & Group B $(n=30)$ & $P$ value \\
\hline Age $\geq 65, \mathrm{n}(\%)$ & $4(20)$ & 19 (63.33) & 0.003 \\
\hline Male gender, n (\%) & $10(50)$ & $17(56.67)$ & 0.643 \\
\hline Underlying disease, n (\%) & & & 0.140 \\
\hline CAD & $0(0)$ & $1(3.33)$ & \\
\hline COPD & $1(5)$ & $0(0)$ & \\
\hline Anemia & $1(5)$ & $0(0)$ & \\
\hline Time since disease onset (days) & $13.25 \pm 2.17$ & $15.17 \pm 4.05$ & 0.059 \\
\hline Fever & $19(95)$ & 28 (93.33) & 1.000 \\
\hline Cough & $13(65)$ & $20(66.67)$ & 0.903 \\
\hline Expectoration & $2(10)$ & $8(26.67)$ & 0.149 \\
\hline Dyspnea & $3(15)$ & $9(30)$ & 0.371 \\
\hline Diarrhoea & $3(15)$ & $3(10)$ & 0.672 \\
\hline Muscle ache & $2(10)$ & $4(13.33)$ & 1.000 \\
\hline Fatigue & $9(45)$ & $9(30)$ & 0.279 \\
\hline Anorexia & $4(20)$ & $5(16.67)$ & 1.000 \\
\hline Clinical severity, n (\%) & & & 0.227 \\
\hline Mild-moderate & 7 (35) & $6(20)$ & \\
\hline Severe & $12(60)$ & $18(60)$ & \\
\hline Critically ill & $1(5)$ & $6(20)$ & \\
\hline
\end{tabular}

Data are expressed as mean \pm SD or number (\%); P values denoted the comparison between $A$ and $B$ subgroups. COVID-19, coronavirus disease 2019; CAD, coronary artery disease; COPD, chronic obstructive pulmonary disease; BP, blood pressure.

We regret the errors.

Open Access Statement: This is an Open Access article distributed in accordance with the Creative Commons AttributionNonCommercial-NoDerivs 4.0 International License (CC BY-NC-ND 4.0), which permits the non-commercial replication and distribution of the article with the strict proviso that no changes or edits are made and the original work is properly cited 
(including links to both the formal publication through the relevant DOI and the license). See: https://creativecommons.org/ licenses/by-nc-nd/4.0/.

\section{References}

1. Huang Z, Cao J, Yao Y, et al. The effect of RAS blockers on the clinical characteristics of COVID-19 patients with hypertension. Ann Transl Med 2020;8:430.

Cite this article as: Huang Z, Cao J, Yao Y, Jin X, Luo Z, Xue Y, Zhu C, Song Y, Wang Y, Zou Y, Qian J, Yu K, Gong H, Ge J. Erratum to the effect of RAS blockers on the clinical characteristics of COVID-19 patients with hypertension. Ann Transl Med 2020;8(17):1119. doi: 10.21037/atm-2020-27 